\title{
Specific DNA probes to detect Escherichia coli strains producing cytotoxic necrotising factor type 1 or type 2
}

\author{
E. OSWALD, $\ddagger$ P. POHL* , E. JACQUEMIN $\dagger$, P. LINTERMANS*, K. VAN MUYLEM* ${ }^{*}$ A. D. O’BRIEN \\ and J. MAINIL†
}

Uniformed Services University of the Health Sciences, Department of Microbiology, 4301 Jones Bridge Road, Bethesda, MD 20814-4799, USA, * Institut National de Recherches Vétérinaires, 99 Groeselenberg. B-1180 Brusse/s and †Université de Liège, Faculté de Médicine Vétérinaire, Sart-Tilman. Bât. B43.B-4000 Liège, Belgium

\begin{abstract}
Summary. Cytotoxic necrotising factors type 1 (CNF1) and type 2 (CNF2) are produced by many Escherichia coli strains isolated from man and animals with intestinal or extra-intestinal colibacillosis. In most laboratories, CNF-producing strains are detected by a cell cytotoxicity assay and confirmed with a neutralisation assay or a mouse footpad assay. In this study, we sought to determine whether DNA probes could detect clinical isolates of $E$. coli producing CNF2 or CNF1, or both, without the need for cell cultures or animal assays. Two internal fragments of the gene encoding CNF2 were used as DNA probes: a 875-bp XhoI-PstI DNA fragment and an adjacent 335-bp PstI-ClaI fragment. A positive response with both DNA probes was associated with CNF2-producing strains, whereas a positive response with only the 335-bp probe was associated with CNF1-producing strains. Results of colony hybridisation experiments with 185 clinical isolates of $E$. coli demonstrated that these DNA probes detected CNF2-producing strains with a sensitivity and specificity of $100 \%$ and CNF1-producing strains with a sensitivity and specificity of $99 \%$. These two DNA probes should greatly facilitate epidemiological studies to assess the importance of CNF-producing strains as agents of diarrhoea and septicaemia.
\end{abstract}

\section{Introduction}

Although Escherichia coli belongs to the normal microflora present in the gastrointestinal tract, certain $E$. coli strains have been associated causally with diarrhoea and extra-intestinal infections in man and animals. During the last 10 years, some of the $E$. coli strains isolated from intestinal or extra-intestinal infections have been reported to produce either cytotoxic necrotising factor type 1 (CNF1) or cytotoxic necrotising factor type 2 (CNF2). ${ }^{1-3}$ CNF1 and CNF2 are two monomeric proteins of $110-115 \mathrm{kDa}^{4-6}$ that induce necrosis in rabbit skin and multinucleation of different eukaryotic cells in culture. ${ }^{1,2,4} \mathrm{CNF} 1$ is chromosomally encoded, ${ }^{7}$ whereas CNF2 is encoded by a transferable F-like plasmid ${ }^{8}$ called Vir. ${ }^{9-11}$

Experimental infections of neonatal calves with strains carrying the Vir plasmid ${ }^{12}$ and of pigs with CNF-producing strains ${ }^{13}$ suggest a role for these toxins in pathogenicity of $E$. coli. Production of CNF1 has been demonstrated in $E$. coli strains from: diarrhoea, ${ }^{1,14}$ urinary tract infections, ${ }^{15,16}$ or bacteraemia in man ; $;^{17} 18$ intestinal or extra-intestinal infections of

Received 20 Dec. 1993; accepted 4 Jan. 1994.

$\dagger$ Present address: Ecole Nationale Veterinaire de Toulouse, Unité Associée INRA de Microbiologie Moléculaire, 23 Chemin des Capelles 31076, Toulouse Cedex, France. cats and dogs $;^{19-21}$ enteritis in piglets $;^{22}$ diarrhoea or bacteraemia, or both, in calves. ${ }^{2,3,20,23,24}$ CNF2producing strains have been isolated from calves and lambs with diarrhoea or bacteraemia, or both. ${ }^{2,3,20,25}$ The results of several epidemiological surveys in Europe indicate that CNF-producing strains could represent $10-50 \%$ of the $E$. coli strains from extraintestinal infections ${ }^{15,17,18}$ and $5-18 \%$ of the $E$. coli strains isolated from diarrhoea. ${ }^{1,3,14,23}$

One difficulty encountered in conducting epidemiological investigations of CNF1 or CNF2 production is that the only in-vitro method for detecting CNF is to prepare a bacterial cell lysate of the test $E$. coli strain and assess the cytotoxic effects of that lysate on tissueculture cells. ${ }^{1}$ Furthermore, most laboratories use neutralisation of the cytotoxicity by specific anti-CNF sera $^{2,3}$ or the CNF2-induced necrosis in mouse footpads $^{26}$ to distinguish CNF1 from CNF2. Recently, techniques for CNF detection have been improved by the use of mitomycin $\mathrm{C}$ to release the toxin into the culture medium ${ }^{1,27}$ and the use of an immunoenzymatic assay to specifically detect CNF1-producing strains ${ }^{28}$ or CNF2-producing strains. ${ }^{29}$ Nevertheless, these biological and immunological assays are timeconsuming and require reagents not readily available to most laboratories. Thus, a rapid and reliable means of detecting strains producing either type of CNF is needed. 
We have recently cloned and sequenced $\operatorname{cnf} 2$, the gene encoding CNF2, from the DNA of a Vir plasmid. ${ }^{30}$ In this study, we sought to determine whether DNA fragments of cnf 2 could be used as DNA probes to detect clinical isolates of $E$. coli producing $\mathrm{CNF} 2$ or $\mathrm{CNF} 1$, or both, by colony hybridisation. Because the nucleotide sequence of $c n f 2$ is $85.7 \%$ identical to that of the recently sequenced gene encoding CNF $1,{ }^{31}$ we anticipated that one part of $c n f 2$ might also react with $c n f l$-containing strains.

\section{Materials and methods}

\section{E. coli strains}

One hundred and eighty-five $E$. coli strains isolated from calves, pigs, cats, dogs and human patients with diarrhoea or extra-intestinal infections were screened with the $c n f$ probes described below. These strains included control strains producing some of the most common toxins produced by $E$. coli: classical heatstable (STaP and STb) and heat-labile (LT-I and LTIIa) enterotoxins; Shiga-like toxins (SLT-I and SLTII) and $\alpha$-haemolysin; 115 of these isolates were tested previously for CNF. ${ }^{19,24,25}$ Seventy E. coli strains were new isolates from colibacillosis cases in Belgium. Three E. coli strains transformed with the Vir plasmids that encode $\mathrm{CNF}^{8,25}$ were also included in this study: strains 711 (pVir) and $\mathrm{H} 209$ (pVir) were obtained from the late H.W. Smith (Houghton Poultry Research Station, Huntingdon). Strain 712(pJL1) was kindly provided by C. L. Gyles (Department of Veterinary Microbiology and Immunology, University of Guelph, Ontario, Canada). Host strain H209 was a non-pathogenic $E$. coli strain isolated from the faeces of a healthy individual. ${ }^{11}$ Host strains $711^{11}$ and $712^{10}$ were two E. coli $\mathrm{K}-12$ strains. The Vir plasmids were isolated from the ovine septicaemic strain $\mathrm{S}^{11}$ and the bovine septicaemic strain JL21. ${ }^{10}$ Three E. coli strains were systematically used as controls in this study: strain 711 as the CNF-negative control, strain 711 (pVir) as the CNF2-positive control, and the previously described wild-type strain $\mathrm{BM} 2-1^{3}$ as the CNF1-positive control.

\section{Cell culture assays}

The $E$. coli isolates were inoculated into $100-\mathrm{ml}$ flasks containing $10 \mathrm{ml}$ of Trypticase Soy Broth (TSB; bioMérieux, Charbonnières-les-Bains, France). Cultures were incubated at $37^{\circ} \mathrm{C}$ for $24 \mathrm{~h}$ with shaking $(160 \mathrm{rpm})$ and then centrifuged at $10000 \mathrm{~g}$ for $20 \mathrm{~min}$. The pellets were resuspended in $1 \mathrm{ml}$ of phosphatebuffered saline, $\mathrm{pH} 7 \cdot 2$ (PBS) containing gentamicin $(100 \mathrm{mg} / \mathrm{L})$ and subjected to two freeze-thaw cycles from $37^{\circ} \mathrm{C}$ to $-20^{\circ} \mathrm{C}$. Extracts were clarified by centrifugation and tested in the HeLa and Vero cell culture assays as described previously. ${ }^{3}$ The CNF2 or CNF1 titre was the highest two-fold dilution of toxic material that caused multinucleation of $50 \%$ of the cells after incubation for $72 \mathrm{~h}$ (cytotoxic dose $50 \%$, CD50). The serum neutralisation titre was defined as the highest dilution of antiserum that neutralised at least $90 \%$ of the multinucleating effect produced by $\mathrm{CNF}$. Neutralising antisera against CNF2 and CNF1 were produced in New Zealand White rabbits by four immunisations consisting of multiple intradermal injections performed at 3-week intervals. ${ }^{8}$

\section{Preparation of DNA probes}

Two internal DNA fragments of $c n f 2$ were cloned into the high copy vector pBluescript II $\mathrm{SK}(+)$ (Stratagene, La Jolla, USA). The resulting recombinant plasmids were designated pEOSW1 and pEOSW3. Plasmid pEOSW1 contained a 335-bp PstIClaI DNA fragment of $c n f 2$ and pEOSW 3 contained an 875-bp XhoI-PstI DNA fragment of cnf2 (fig. 1). The $c n f 2$ DNA inserts in pEOSW1 and pEOSW3 were isolated by restriction endonuclease digestion of the plasmid DNA followed by gel electrophoresis and electro-elution. ${ }^{32}$ These DNA fragments were then radiolabelled with $\left[\alpha^{32} \mathrm{P}\right]$-deoxynucleotide triphosphates according to the directions supplied in a multiprimer DNA labelling kit (Boehringer, Brussels, Belgium).

\section{Colony hybridisations}

DNA colony hybridisations were accomplished as described previously. ${ }^{33}$ Whatman 541 paper filters (Belgolabo, Belgium) were placed on to colonies grown overnight on Luria-Bertani agar. After $2 \mathrm{~h}$, the papers were peeled off and placed colony-side up on to Whatman 3MM paper saturated with the following solutions: sodium dodecyl sulphate (SDS) $10 \% \mathrm{w} / \mathrm{v}$ for $3 \mathrm{~min}, 0.5 \mathrm{M} \mathrm{NaOH}$ for $15 \mathrm{~min}$ and $1.0 \mathrm{M}$ Tris- $\mathrm{HCl}$ $(\mathrm{pH} 7 \cdot 6)-1.5 \mathrm{M} \mathrm{NaCl}$ for $5 \mathrm{~min}$, twice. The filters were allowed to dry and hybridised overnight with the DNA probes at $65^{\circ} \mathrm{C}$ in a solution comprising $3 \times \mathrm{SSC}$ $(0.45 \mathrm{M} \mathrm{NaCl}-0.045 \mathrm{M}$ sodium citrate), $10 \times$ Denhardt solution, ${ }^{32}$ SDS $0.1 \% \mathrm{w} / \mathrm{v}$ and salmon sperm DNA $1 \% .^{32}$ The filters were washed three times for $30 \mathrm{~min}$ at $65^{\circ} \mathrm{C}$ in $3 \times \mathrm{SSC}$ containing SDS $0.1 \%$, and then subjected to autoradiography.

\section{Plasmid hybridisation assay}

Plasmid DNA was extracted from lysed bacteria according to the method of Kado and Liu. ${ }^{34}$ Plasmids were separated by electrophoresis overnight at $4^{\circ} \mathrm{C}$ in an agarose $0.5 \%$ gel. The DNA within the gels was denatured and the gels were dried. ${ }^{35}$ The gels were subsequently hybridised in situ with the DNA probe under the hybridisation conditions described above.

\section{Evaluation criteria}

The standard cytotoxic assay in combination with seroneutralisation was the reference assay for the detection of CNF1 and CNF2 phenotype. The sen- 


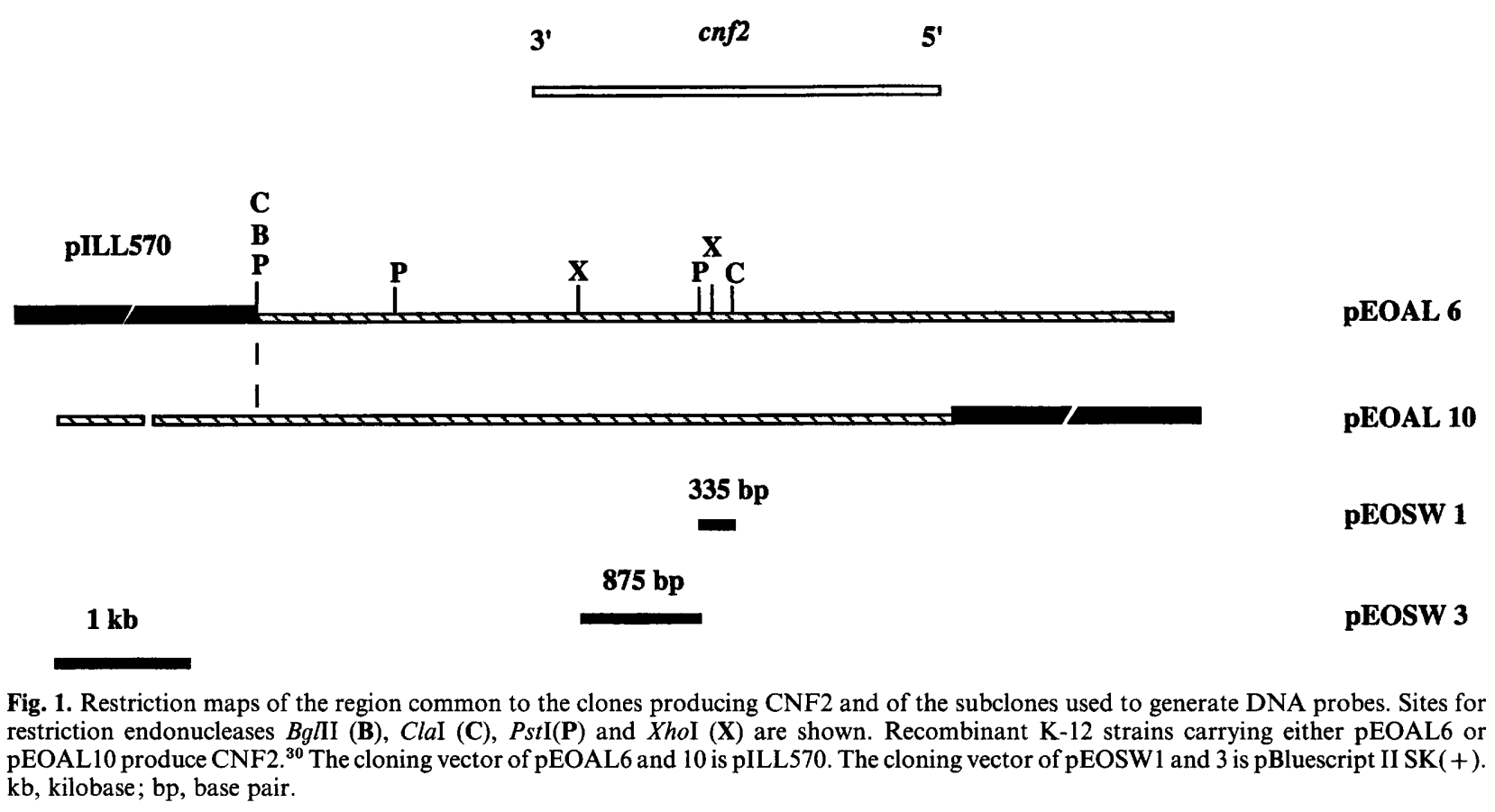

Table I. Distribution of hybridisation results with the DNA probes derived from pEOSW 3 and pEOSW1 according to the CNF phenotype of the $185 \mathrm{E}$. coli strains tested

\begin{tabular}{lccc}
\hline \multirow{2}{*}{ E. coli phenotype } & Number tested & \multicolumn{2}{c}{ Number positive with probe (reaction intensity) } \\
\cline { 3 - 4 } & & pEOSW1 & pEOSW3 \\
\hline Non-CNF producer & 64 & $1(+)$ & 0 \\
CNF1-producer & 67 & $66(+)$ & 0 \\
CNF2-producer & 54 & $54(+++)$ & $51(+++)$ \\
& & & $3(++)$ \\
\hline
\end{tabular}

Table II. Sensitivity and specificity of the detection of CNF-producing $E$. coli by colony hybridisation with the DNA probes derived from pEOSW3 and pEOSW1

\begin{tabular}{lccc}
\hline Parameters selected & Phenotype expected & Sensitivity (\%) & Specificity (\%) \\
\hline $\begin{array}{c}\text { Positive with probes from } \\
\text { pEOSW3 and pEOSW1 }\end{array}$ & CNF2-producer & 100 & 100 \\
$\begin{array}{l}\text { Positive with probe from } \\
\text { pEOSW1 and negative with } \\
\text { probe from pEOSW3 }\end{array}$ & CNF1-producer & 99 & 99 \\
\hline
\end{tabular}

sitivity and specificity of CNF detection with the $c n f$ DNA probes were calculated as follows and converted to percentages: sensitivity $=\mathrm{TP} /(\mathrm{TP}+\mathrm{FN})$ and specificity $=\mathrm{TN} /(\mathrm{TN}+\mathrm{FP})$, where $\mathrm{TP}$ is true positive, $\mathrm{TN}$ is true negative, FP is false positive and FN is false negative.

\section{Results}

Two internal DNA fragments of $c n f 2$ were constructed for use as probes for CNF-producing strains: a 875-bp XhoI-Pst I fragment isolated from pEOSW3 and an adjacent 335-bp Pst I-ClaI fragment isolated from pEOSW1 (fig. 1). Three pairs of Vir transconjugant strains and a collection of $185 \mathrm{E}$. coli strains isolated from calves, pigs, cats, dogs and human patients with diarrhoea or extra-intestinal infections were used to test the sensitivity and specificity of the detection of CNF-producing strains by colony hybridisation. The HeLa cell cytotoxic assay in combination with seroneutralisation was the reference assay for the detection of CNF1 and CNF2. This standard assay was used to divide the collection of $E$. 

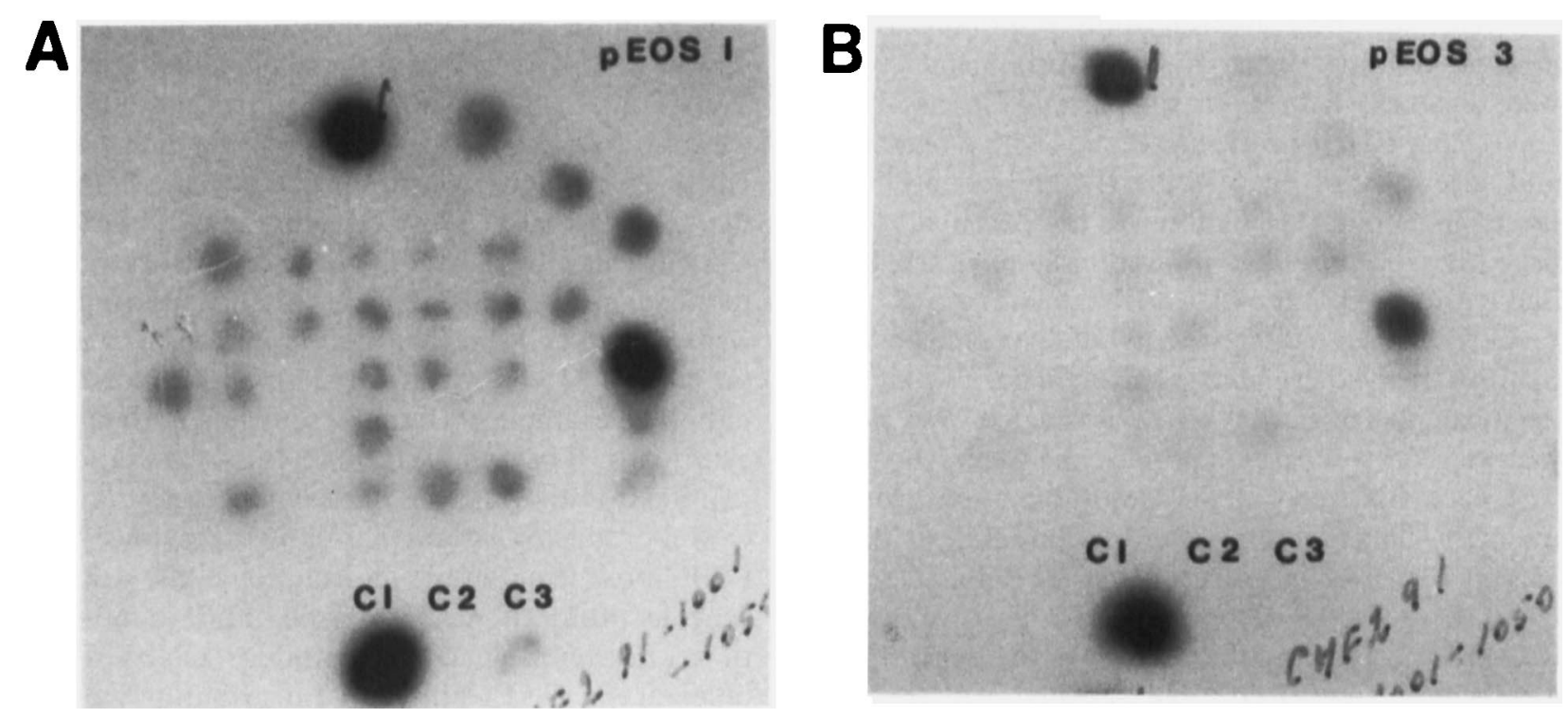

Fig. 2. Autoradiographs of two identical blots of $48 \mathrm{E}$. coli strains isolated from calves with diarrhoea or cases of septicaemia. C1, CNF2positive control; C2, CNF-negative control; C3, CNF1-positive control. Panel A, colony hybridisation with the PstI-ClaI fragment of pEOSW1; B, colony hybridisation with the Xhol-PstI fragment of pEOSW3. The two isolates that gave black spots with both probes were identified as CNF2-producers in the seroneutralisation assay. The 26 isolates that gave grey spots with the probe derived from pEOSW1 were identified as CNF1-producers in the seroneutralisation assay. The 22 other isolates were CNF-negative in the cytotoxic assays.

A

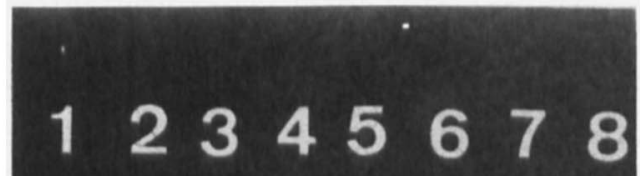

B
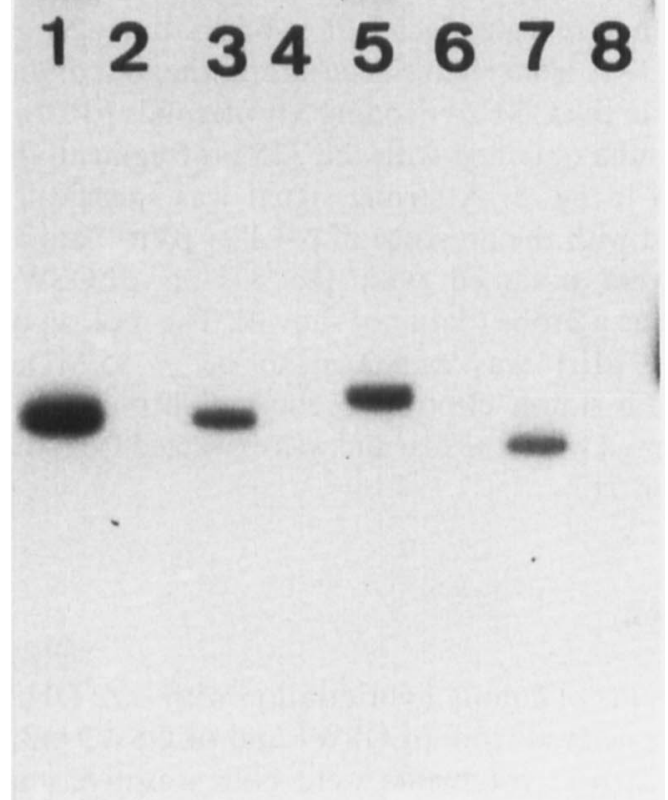

Fig. 3. Hybridisation of different Vir plasmids of E. coli with the probe derived from pEOSW1. A, agarose gel electrophoresis of plasmid extracts of eight $E$. coli strains; B, autoradiograph of the same gel hybridised with the probe derived from pEOSW1. The plasmid DNA preparations were from the following $E$. coli strains: lane 1, S5, a CNF2-producer; 2, 712, a K-12 strain; 3, H209(pVir), a CNF2-producer; 4, H209, a human normal flora isolate; 5, 712(pJL1), a CNF2-producer; 6, JL21vir, CNF negative; 7, JL21 vir ${ }^{+}$, a CNF2-producer; 8, strain 712 .

coli clinical isolates into 64 non-CNF producers, 67 CNF1-producers, and 54 CNF2-producers. Results of colony hybridisation experiments with these $185 E$. coli strains indicated that the 875 -bp XhoI-Pst I frag- ment specifically hybridised with the CNF2-producing strains, whereas the adjacent 335-bp PstI-ClaI fragment hybridised with both CNF1-producing and CNF2-producing strains (table I). By selecting one or 
the other of these hybridisation responses as the positive response criteria, CNF2-producing strains were detected with a sensitivity and specificity of $100 \%$, and CNF1-producing strains with a sensitivity and specificity of $99 \%$ (table II). Only one CNF1producing strain (115KH89) was not detected by any probe and one non-CNF producer (436KH89) hybridised with the 335-bp Pst $\mathrm{I}-\mathrm{ClaI}$ fragment.

An example of the results observed in colony hybridisation experiments is shown in fig. 2 where two identical blots of $48 E$. coli strains isolated from calves with diarrhoea or cases of septicaemia were hybridised with each CNF probe. The autoradiograph in fig. 2 (panel A) depicts colony hybridisation results with the 335-bp PstI-ClaI fragment. The CNF2-positive control (C1) gave a black spot, the CNF-negative control (C2) gave no spot and the CNF1-positive control (C3) gave a grey spot. Two CNF2-positive isolates gave black spots, 26 CNF1-positive isolates gave grey spots, and 22 negative isolates gave no spot at all. The autoradiograph in fig. 2 (panel B) is the result of colony hybridisation with the 875-bp XhoI-PstI fragment. The CNF2-positive control $(\mathrm{Cl})$ gave a black spot. The CNF-negative control (C2) and the CNF1positive control (C3) gave no spots. The two CNF2positive isolates gave black spots with the 875-bp XhoI-PstI fragment, the $26 \mathrm{CNF} 1$-positive isolates gave very faint or no spots, and the 22 negative isolates gave no spot at all.

To further characterise the CNF probes as genetic tools, both were tested by in-situ hybridisation against plasmid DNA from eight $E$. coli strains that did or did not contain the CNF2-encoding Vir plasmids $\mathrm{pJL} 1$ or pVir. Results obtained with the 335-bp fragment are presented in fig. 3. A strong signal was specifically associated with the presence of pJL1 or pVir. Similar results were obtained with the 875-bp pEOSW3 fragment as a probe (data not shown). The mol. wt of $\mathrm{pVir}$ and $\mathrm{pJL} 1$ was estimated to be $c .85 \mathrm{MDa}$. However, a slower electrophoretic mobility of $\mathrm{pJL} 1$ was observed when the plasmid was extracted from the K12 strain 712 .

\section{Discussion}

The results of colony hybridisation with $c n f 2$ DNA fragments derived from pEOSW1 and pEOSW3 indicated that these fragments were both sensitive and specific as probes for detecting CNF1- and CNF2producing strains of $E$. coli. A positive response with both probes was associated with CNF2-producers, whereas a positive response with the probe derived from pEOSW1 alone was associated with CNF1producers. Because the seroneutralisation assay confirmed the phenotype of the strains detected with the two DNA probes derived from pEOSW1 and pEOSW3, we believe that these cnf probes can be used in place of animal assays and cell-culture assays for the detection of CNF-producing strains.
For some E. coli strains, colony hybridisation results may be more accurate than the cell cytotoxicity assay. For example, one isolate that produces a Shiga-like toxin (verotoxin) reacted strongly with both probes. However, no multinucleation effect was detectable on the cell cytotoxicity assay because the cell monolayer was destroyed by the Shiga-like toxin. By neutralising the toxic effect of SLT with a specific antiserum, we were able to confirm that this strain also produced a fully active CNF2 cytotoxin. This strain is the only published example of a strain producing both of these cytotoxins. The significance of this observation in relation to pathogenesis is unclear. Characterisation of CNF2-producing strains has shown previously that CNF2-producing strains do not constitute a homogeneous group of $E$. coli ${ }^{25}$ a finding in contrast to those $E$. coli isolates that produce CNF1. ${ }^{24}$ This difference in CNF1 and CNF2 distribution amongst $E$. coli strain types may be related to the fact that CNF2 is encoded by a transferable F-like plasmid, ${ }^{8,10,11}$ whereas CNF1 is chromosomally encoded. ${ }^{7}$ However, even with the potential mobility of $\operatorname{cnf} 2$, the production of both CNF2 and SLT by the same strain remains a rare event.

Both probes were also used successfully to detect the large Vir plasmids coding for CNF2.$^{6,8}$ The estimated mol. wt of pVir and pJLl ( $85 \mathrm{MDa})$ is similar to the $92 \mathrm{MDa}$ reported previously. ${ }^{10}$ Curiously, we noticed a slight variation in the electrophoretic mobility of pJL1 when the plasmid was extracted from the $E$. coli $\mathrm{K} 12$ strain 712 . This variation may reflect a difference in pJL1 supercoiling when the plasmid is resident in recipient $E$. coli $\mathrm{K} 12$ strain 712 compared to wild-type $E$. coli strain JL21. Alternatively, the plasmid may have undergone some spontaneous deletion in the wild-type background. To test this possibility, we are in the process of analysing the restriction maps of both forms of $\mathrm{pJL} 1$.

The sequences of the CNF toxin genes are $85.7 \%$ identical. ${ }^{30,31}$ The results of this study confirmed the close relationship at the DNA level between CNF1 and CNF2. Indeed, a 335-bp internal fragment of the gene coding for CNF2 identified CNF1-producing strains. However, CNF1-producing strains did not hybridise with the second probe, an adjacent 875-bp internal fragment of $\operatorname{cnf} 2$. Computer analysis showed less mismatching between the smaller DNA probe and cnfl: the 335-bp and the 875-bp DNA probes are, respectively, $88.2 \%$ and $86.8 \%$ identical to similar fragments of cnfl. Recently, Falbo et al. reported that they were unable to detect three CNF2-producing strains with four large fragments of cnf $1 .{ }^{31}$ Little information about the hybridisation conditions used by these investigators was given, but two of their DNA probes contained part of the upstream and downstream regions of the CNF1 toxin gene. These regions diverge between $c n f 1$ and $c n f 2 .{ }^{30,31}$ Since $c n f l$ and $c n f 2$ have a low GC content of $35 \%$, we think that both the size of the probes and the hybridisation conditions (absence of formamide in our hybridisation solution) 
are critical parameters for the detection of CNFproducing strains by colony hybridisation.

We are now using the two DNA probes routinely for the detection of CNF-producing strains. As colony blots can be duplicated easily and used with other DNA probes, we are testing a large collection of $E$. coli isolates with DNA probes for CNFs and other potential virulence factors. Our preliminary results confirm that CNF1 and $\alpha$-haemolysin production are closely linked ${ }^{7,16}$ and that a majority of CNF2- producing strains also produce an F17-like adhesin. ${ }^{25}$ Large scale use of these probes will greatly facilitate estimation of the incidence of CNF-producing strains among clinical isolates of $E$. coli.

We thank Clare Schmitt for critically reviewing the manuscript. This work was supported in part by a grant from the US Department of Agriculture (MDR-9203162) and by the Institut National de la Recherche Agronomique (France). The opinions or assertions contained herein are the private views of the authors and are not to be construed as official or as reflecting the views of the Department of Defense.

\section{References}

1. Caprioli A, Falbo V, Roda LG, Ruggeri FM, Zona C. Partial purification and characterization of an Escherichia coli toxic factor that induces morphological cell alterations. Infect Immun 1983; 39: 1300-1306.

2. De Rycke J, González EA, Blanco J, Oswald E, Blanco M, Boivin R. Evidence of two types of cytotoxic necrotizing factor in human and animal clinical isolates of Escherichia coli. J Clin Microbiol 1990; 28: 694-699.

3. De Rycke J, Guillot JF, Boivin R. Cytotoxins in nonenterotoxigenic strains of Escherichia coli isolated from faeces of diarrheic calves. Vet Microbiol 1987; 15: 137-150.

4. Caprioli A, Donelli G, Falbo V et al. A cell division-active protein from E. coli. Biochem Biophys Res Commun 1984; 118: 587-593.

5. De Rycke J, Phan-Thanh L, Bernard S. Immunochemical identification and biological characterization of cytotoxic necrotizing factor from Escherichia coli. J Clin Microbiol 1989; 27: 983-988.

6. Oswald E, De Rycke J. A single protein of $110 \mathrm{kDa}$ is associated with the multinucleating and necrotizing activity coded by the Vir plasmid of Escherichia coli. FEMS Microbiol Lett $1990 ; 68: 278-284$

7. Falbo V, Famiglietti M, Caprioli A. Gene block encoding production of Cytotoxic Necrotizing Factor 1 and hemolysin in Escherichia coli isolates from extraintestinal infections. Infect Immun 1992; 60: 2182-2187.

8. Oswald E, De Rycke J, Guillot JF, Boivin R. Cytotoxic effect of multinucleation in HeLa cell cultures associated with the presence of Vir plasmid in Escherichia coli strains. FEMS Microbiol Lett 1989; 58: 95-100.

9. Lopez-Alvarez J, Gyles CL. Occurrence of the Vir plasmid among animal and human strains of invasive Escherichia coli. Am J Vet Res 1980; 41 : 769-774.

10. Lopez-Alvarez J, Gyles CL, Shipley PL, Falkow S. Genetic and molecular characteristics of the Vir plasmids of bovine septicemic Escherichia coli. J Bacteriol 1980; 141 : 758-769.

11. Smith HW. A search for transmissible pathogenic characters in invasive strains of Escherichia coli: the discovery of a plasmid-controlled toxin and a plasmid-controlled lethal character closely associated, or identical, with Colicine V. $J$ Gen Microbiol 1974; 83: 95-111.

12. Smith HW. Observations on Escherichia coli infection in calves. In: Rutter JM (ed) Proceedings of the first seminar on "pathology" in the CEC programme of coordination of research in beef production. Perinatal ill-health in calves. 1975: 47-59.

13. Wray C, Piercy DWT, Carroll PJ, Cooley WA. Experimental infection of neonatal pigs with CNF toxin-producing strains of Escherichia coli. Res Vet Sci 1993; 54: 290-298.

14. Bisicchia R, Ciammarughi R, Caprioli A, Falbo V, Ruggeri FM. Toxin production and haemagglutination in strains of Escherichia coli from diarrhoea in Brescia, Italy. $J$ Hyg 1985; 95: 353-361

15. Alonso MP, Blanco J, Blanco M, González EA. Frequent production of toxins by Escherichia coli strains isolated from human urinary tract infections: relation with haemagglutination. FEMS Microbiol Lett 1987; 48: 391-396.

16. Caprioli A, Falbo V, Ruggeri FM et al. Cytotoxic necrotizing factor production by hemolytic strains of Escherichia coli causing extraintestinal infections. J Clin Microbiol 1987; 25: $146-149$.

17. Blanco J, Alonso MP, Gonzales EA, Blanco M, Garabal JI. Virulence factors of bacteremic Escherichia coli with particular reference to production of cytotoxic necrotizing factor (CNF) by P-fimbriate strains. J Med Microbiol $1990 ; 31: 175-183$.

18. Cherifi A, Contrepois M, Picard B et al. Factors and markers of virulence in Escherichia coli from human septicemia. FEMS Microbiol Lett 1990; 70: 279-284.

19. Pohl P, Mainil J, Devriese L et al. Escherichia coli productrices de la toxine cytotoxique nécrosant de type 1 (CNF1) isolées à partir de processus pathologiques chez des chats et des chiens. Ann Méd Vét 1992; 137: 21-25.

20. Pohl P, Oswald E, Van Muylem K, Jacquemin E, Lintermans P, Mainil J. Escherichia coli producing CNF1 and CNF2 cytotoxins in animals with different disorders. Vet Res (in press). 1993; 24: 311-315.

21. Prada J, Baljer G, De Rycke J et al. Characteristics of alphahemolitic strains of Escherichia coli isolated from dogs with gastroenteritis. Vet Microbiol 1991; 29: 59-73.

22. González EA, Blanco J. Production of cytotoxin VT in enteropathogenic and non-enteropathogenic Escherichia coli strains of porcine origin. FEMS Microbiol Lett 1985; 26: $127-129$

23. Blanco J, González EA, Blanco M, Regueiro B, Bernardez I. Production of toxins by Escherichia coli strains isolated from calves with diarrhoea in Galicia (north-western Spain). Vet Microbiol 1988; 18: 297-311.

24. Pohl P, Daube G, Lintermans P, Kaeckenbeeck A, Mainil J, Oswald E. Facteurs de virulence et phénotypes de soixante et une souches d'Escherichia coli d'origine bovine, productrices de la toxine cytotoxique nécrosante de type 1 (CNF1). Ann Rech Vét 1991; 23: 83-91.

25. Oswald E, De Rycke J, Lintermans P et al. Virulence factors associated with the cytotoxic necrotizing factor type two in bovine diarrheic and septicemic strains of Escherichia coli. J Clin Microbiol 1991; 29: 2522-2527.

26. De Rycke J, Oswald E, Boivin R. An in vivo assay for the detection of cytotoxic strains of Escherichia coli. Ann Rech Vet 1989; 20: 39-46.

27. Blanco J, Blanco M, González EA, Alonso MP, Garabal JI. Comparative evaluation of three tests for the detection of Escherichia coli cytotoxic necrotizing factors (CNF1 and CNF2) using filtrates of cultures treated with mitomycin C. FEMS Microbiol Lett 1990; 69: 311-316.

28. Tabouret M, De Rycke J. Detection of cytotoxic necrotising factor (CNF) in extracts of Escherichia coli strains by enzyme-linked immunosorbent assay. $J$ Med Microbiol $1990 ; 32$ : 73-81.

29. Oswald E, Tabouret M, Boivin R, De Rycke J. Detection of Escherichia coli strains producing cytotoxic necrotizing factor type two (CNF2) by enzyme-linked immunosorbent assay. Vet Microbiol (in press). 1994; (in press).

30. Oswald E, Sugai M, Labigne A et al. Cytotoxic necrotizing factor type 2 produced by virulent Escherichica coli modifies the small GTP-binding proteins Rho involved in actin stress fibers assembly. Proc Natl Acad USA (in press). 1994; 91 : (in press). 
31. Falbo V, Pace T, Picci L, Pizzi E, Caprioli A. Isolation and nucleotide sequence of the gene encoding cytotoxic necrotizing factor 1 of Escherichia coli. Infect Immun, 1993; 61: $4909-4914$.

32. Sambrook J, Fritsch EF, Maniatis T. Molecular cloning: a laboratory manual. Cold Spring Harbor, NY, Cold Spring Harbor Laboratory. 1989.

33. Mainil J, Bex G, Jacquemin E, Pohl P, Couturier M, Kaeckenbeeck A. Prevalence of four enterotoxins (STaP,STaH, $\mathrm{STb}$ and LT) and four adhesin subunits (K99, K88, 987P, and F41) gene among Escherichia coli isolate from cattle. Am J Vet Res 1990; 51: 187-190.

35. Kado CI, Liu S-T. Rapid procedure for detection and isolation of large and small plasmids. $J$ Bacteriol 1981; 145: 1365-1373.

36. Broes A, Fairbrother JM, Mainil J, Harel J, Lariviere S. Phenotypic and genotypic characterization of enterotoxigenic Escherichia coli serotype 08:KX105 and O8:K " 2829 " strains isolated from piglets with diarrhea. J Clin Microbiol 1988; 26: 2402-2409. 